\title{
CORRESPONDENCE
}

\section{Effectiveness of amitriptyline and lamotrigine in neuropathic pain after traumatic spinal cord injuries}

Spinal Cord Series and Cases (2017) 3, 16036; doi:10.1038/ scsandc.2016.36; published online 18 May 2017

The study by Agarwal and Joshi ${ }^{1}$ reports the effectiveness of amitriptyline and lamotrigine in neuropathic pain after traumatic spinal cord injuries. Current available evidence, as demonstrated in a recently published guideline for management of neuropathic pain in spinal cord injury, ${ }^{2}$ is scarce regarding comparison of two different drugs, as they focus on placebo controlled trials. Amitriptyline was compared to gabapentin and diphenhydramine as an active placebo on a small trial. ${ }^{3}$ Lamotrigine was only compared to placebo, and demonstrated to be effective in patients with incomplete lesion just after a post hoc analysis. ${ }^{4}$

Although Agarwal's trial sums to this body of evidence, the clinical information that can be extracted is uncertain. The Shortform MCGill Pain Questionnaire-2, chosen as a neuropathic pain measurement, has a good interobserver correlation, but until now a minimal clinically important difference has not been established. $^{5}$

The authors did not clearly report which of the outcomes was considered to be the primary outcome, and they also didn't report study power (neither pre-determined nor post hoc) for the outcomes assessed. Since the study is categorized as randomized, it would be of great interest to have patient characteristics and their distribution in both the amitriptyline and lamotrigine treatment groups available in the article. ${ }^{6}$

Unfortunately, spinal cord-related neuropathic pain treatment still lacks a strong body of evidence. This is an interesting study with a direct comparison of two drugs. Addressing these issues would be helpful for a better understanding of the reported results. Also, in times of systematic reviews, it would be interesting to have these questions answered.

\section{COMPETING INTERESTS}

The authors declare no conflict of interest.

Rodrigo L Almeida and Paulo S Beraldo Department of Spinal Cord Injury/SARAH Rehabilitation Hospital Network/SARAH Brasilia, Brasilia, Distrito Federal, Brazil Correspondence: RL Almeida (lanna.rodrigo@gmail.com)

\section{REFERENCES}

1 Agarwal N, Joshi M. Effectiveness of amitriptyline and lamotrigine in traumatic spinal cord injury-induced neuropathic pain: a randomized longitudinal comparative study. Spinal Cord 2017; 55: 126-130.

2 Guy SD, Mehta S, Casalino A, Côté I, Kras-Dupuis A, Moulin DE et al. The CanPain SC clinical practice guidelines for rehabilitation management of neuropathic pain after. Spinal Cord 2016; 54(Suppl 1): S14-S23.

3 Rintala DH, Holmes SA, Courtade D, Fiess RN, Tastard LV, Loubser PG. Comparison of the effectiveness of amitriptyline and gabapentin on chronic neuropathic pain in persons with spinal cord injury. Arch Phys Med Rehabil 2007; 88: 1547-1560.

4 Finnerup NB, Sindrup SH, Bach FW, Johannesen IL, Jensen TS. Lamotrigine in spinal cord injury pain: a randomized controlled trial. Pain 2002; 96: 375-383.

5 Nayak NR, Coats JM, Abdullah KG, Stein SC, Malhotra NR. Tracking patient-reported outcomes in spinal disorders. Surg Neurol Int 2015; 6(Suppl 19): S490-S499.

6 Pocock SJ, Stone GW. The primary outcome fails-What next? N Engl J Med 2016; 375: 861-870. 